\title{
The effect of crop plant on soil mesofauna diversity
}

\section{Wpływ rośliny uprawnej na zróżnicowanie mezofauny glebowej}

\author{
Iwona Gruss, Michał Hurej, Jacek Twardowski
}

\section{Summary}

The aim of the study was the quantitative and qualitative comparison of springtail and mite assemblages on the field of potatoes and winter rye. The field experiment was carried out at the Experimental Station of Warsaw University of Life Sciences in Skierniewice, in 2010-2012. Soil samples were collected to a depth of $10 \mathrm{~cm}$ from plots of potato and winter rye grown in a five-crop rotation in spring and autumn each year of the experiment. Mesofauna representatives were extracted from the soil using Tullgren apparatus. Springtails were identified to family level, mites to orders. In all sampling dates springtails were more abundant in winter rye, than in potato crop. In potato samples identified Collembola represented 5 families: Hypogastrudidae, Brachystomellidae, Isotomidae, Onychiuridae and Sminthuridae. Additionally, in winter rye representatives of the family Entomobrydidae were identified. The average number of mites was higher in potato crop than in winter rye. In potato the most abundant groups were mites from Prostigmata and Astigmata orders, while in winter rye from Astigmata and Gamasida orders.

Key words: springtails, mites, soil mesofauna, potato, winter rye, five-crop rotation

\section{Streszczenie}

Celem badań było ilościowe i jakościowe porównanie zgrupowań skoczogonków i roztoczy na plantacji ziemniaka i żyta ozimego. Doświadczenie polowe prowadzono na terenie Stacji Doświadczalnej w Skierniewicach, należącej do Szkoły Głównej Gospodarstwa Wiejskiego w Warszawie, w latach 2010-2012. Próby glebowe pobierano do głębokości $10 \mathrm{~cm}$ z plantacji ziemniaka i żyta ozimego uprawianych w pięciopolowym płodozmianie, wiosną i jesienią każdego roku badań. Przedstawicieli mezofauny wypłaszano z gleby z wykorzystaniem aparatów Tullgrena. Skoczogonki oznaczano do rodzin, roztocze do rzędów. We wszystkich terminach pobierania prób skoczogonki były znacznie liczniejsze w uprawie żyta ozimego, niż w uprawie ziemniaka. W próbach pochodzących z ziemniaka stwierdzono występowanie skoczogonków należących do 5 rodzin: Hypogastrudidae, Brachystomellidae, Isotomidae, Onychiuridae i Sminthuridae. W uprawie żyta ozimego dodatkowo wyróżniono rodzinę Entomobrydidae. Średnia liczebność roztoczy była wyraźnie wyższa w uprawie ziemniaka, niż żyta ozimego. W przypadku ziemniaka najliczniej stwierdzano roztocze z rzędów Prostigmata i Astigmata, w uprawie żyta ozimego natomiast licznie występowały roztocze z rzędów Astigmata i Gamasida.

Słowa kluczowe: skoczogonki, roztocze, mezofauna glebowa, ziemniak, żyto ozime, płodozmian pięciopolowy

Uniwersytet Przyrodniczy we Wrocławiu

Katedra Ochrony Roślin

PI. Grunwaldzki 24A, 50-363 Wrocław

iwona.gruss@up.wroc.pl 


\section{Wstęp / Introduction}

Skoczogonki i roztocze to organizmy należące do mezofauny, w ścisły sposób związane $\mathrm{z}$ właściwościami gleby i jej zasobnością w składniki pokarmowe. Stawonogi te wyraźnie reagują na zmiany parametrów fizykochemicznych gleby, szczególnie wilgotności, zawartości próchnicy i odczynu. Ich występowanie jest również uzależnione od doboru roślin w płodozmianie, systemu uprawy roli, warunków pogodowych, typu gleby, a także terminu pobierania prób (Alvarez i wsp. 2001; Twardowski 2010). W literaturze brakuje opracowań dotyczących wpływu rośliny uprawnej na występowanie skoczogonków i roztoczy.

Skoczogonki (Hexapoda: Collembola) i roztocze (Arachnida: Acari) mogą stanowić do 95\% mezofauny glebowej (Neher i Barbercheck 1999). Zdecydowana większość z nich występuje do głębokości $10 \mathrm{~cm}$, a liczebność na metrze kwadratowym w glebie na polu uprawnym może wynosić od 10000 do 120000 (Filser i Fromm 1995; Axelsen i Thorup-Kristensen 2000). Zarówno wśród skoczogonków, jak i roztoczy znane są formy wyspecjalizowane pokarmowo, jak i polifagiczne (Edwards 1999). Luxton (1982) podaje, że około 80\% mezofauny glebowej odżywia się mikroorganizmami, a 20\% należy do form saprofagicznych. Większość Acari jednak odżywia się mikroflorą, natomiast Collembola grzybami (Buscot i Varna 2005). Jako saprofagi, skoczogonki i roztocze regulują przepływ materii i energii W detrytusowej sieci troficznej, przyśpieszają tempo dekompozycji substancji organicznej oraz wpływają na uwalnianie biogenów (Rusek 1998; Boczek i Błaszak 2005). Szczególnie występowanie roztoczy z rzędu Oribatida określa się jako ważny czynnik glebotwórczy, sprzyjający powstawaniu struktury gruzełkowatej gleby. Ważną grupę, zarówno wśród roztoczy, jak i skoczogonków, stanowią drapieżcy odpowiadający za utrzymanie równowagi biologicznej w glebie uprawnej (BehanPelletier 1999; Koehler 1999; Boczek i Błaszak 2005).

Celem badań było ilościowe i jakościowe porównanie zgrupowań skoczogonków i roztoczy w uprawie ziemniaka i żyta ozimego.

\section{Materiały i metody / Materials and methods}

Doświadczenie prowadzono w latach 2010-2012, na terenie Stacji Doświadczalnej w Skierniewicach, należącej do Wydziału Rolnictwa i Biologii Szkoły Głównej Gospodarstwa Wiejskiego w Warszawie. Próby glebowe pobierano ze statycznego doświadczenia nawozowego, założonego w 1922 roku, metodą losowanych podbloków, w pięciu powtórzeniach. Badania prowadzono na plantacji ziemniaka odmiany Bila i żyta ozimego odmiany Dańkowskie Złote, uprawianych w pięciopolowym płodozmianie (ziemniaki - 30 ton obornika, jęczmień jary, koniczyna czerwona, pszenica ozima, żyto ozime). W doświadczeniu na całej powierzchni pola stosowano standardowe nawożenie CaNPK. Pod względem granulometrycznym glebę $\mathrm{w}$ doświadczeniu określono jako piasek gliniasty mocny i zaliczono do II klasy bonitacyjnej (zarówno w uprawie ziemniaka, jak i żyta ozimego). W latach 2010 i 2011 glebę pobierano w jednym terminie wiosną oraz w jednym terminie jesienią, natomiast w 2012 roku próby pobierano dwukrotnie wiosną i dwukrotnie jesienią. W przypadku żyta ozimego termin pobierania prób jesienią przypadał na fazę pierwszego liścia (BBCH 11), natomiast wiosną na koniec krzewienia, początek wydłużania się pędów, tj. fazę rozwoju BBCH 25-30. W kombinacji $\mathrm{z}$ ziemniakiem próby wiosną pobierano przed sadzeniem bulw, natomiast jesienią po ich zbiorze.

Powierzchnia poletka doświadczalnego wynosiła $36 \mathrm{~m}^{2}$ $(12 \times 3 \mathrm{~m})$. Na każdym z 5 poletek obu kombinacji, po jego przekątnej, każdorazowo pobierano po 5 prób gleby. Do tego celu użyto pobieraka o średnicy $5 \mathrm{~cm}$ i głębokości $10 \mathrm{~cm}$. We wszystkich terminach badań analizowano 25 prób gleby z każdej kombinacji. Stawonogi wypłaszano z gleby w laboratorium, w aparatach Tullgrena, zmodyfikowanych przez Murphy'ego (1956). Czas wystawienia gleby na działanie światła i temperatury (żarówki $25 \mathrm{~W})$ wynosił $24 \mathrm{~h}$. Odłowione stawonogi przechowywano w 75\% alkoholu etylowym. Skoczogonki oznaczono do rodzin, korzystając z kluczy Pomorskiego (1998), Potapova (2001) i Hopkina (2007). Roztocze oznaczono do czterech rzędów, tj. Astigmata, Prostigmata, Oribatida, Gamasida (Boczek i Błaszak 2005). Obliczenia statystyczne (ANOVA, test Tukeya $\mathrm{p} \leq 0,05$ ), wykonano w programie Statistica 9.0.

\section{Wyniki i dyskusja / Results and discussion}

Skoczogonki. Łącznie w ciągu całego okresu badań, z gleby pobranej z uprawy ziemniaka wypłoszono 202 skoczogonki, natomiast z żyta ozimego 1087 tych stawonogów (tab. 1). We wszystkich terminach pobierania prób Collembola były wyraźnie liczniejsze w uprawie żyta ozimego, w porównaniu do ziemniaka. Jednak tylko $\mathrm{w}$ jednym przypadku, tj. w pierwszym terminie pobierania prób jesienią 2012 roku, różnice między tymi kombinacjami były istotne (średnio 2,2 osobników w uprawie ziemniaka i 22,2 w uprawie żyta).

$\mathrm{Na}$ rysunku 1. przedstawiono porównanie liczebności skoczogonków oznaczonych do rodzin w glebie pobranej z uprawy ziemniaka oraz żyta ozimego. W przypadku ziemniaka Collembola oznaczono do pięciu rodzin, tj. Hypogastrudidae, Brachystomellidae, Isotomidae, Onychiuridae i Sminthuridae. W uprawie żyta ozimego dodatkowo wyróżniono rodzinę Entomobrydidae. W glebie pobranej z uprawy ziemniaka 36\% wszystkich skoczogonków stanowiła rodzina Isotomidae (łącznie 87 skoczogonków). W dalszej kolejności oznaczono osobniki należące do rodzin Onychiuridae (28\% - 67 osobników), Sminthurididae (19\% - 48 osobników) i Hypogastrudidae (15\% - 36 osobników). W przypadku żyta ozimego najliczniej występowały skoczogonki oznaczone do rodziny Onychiuridae $(40 \%-432$ skoczogonki), następnie Hypogastrudidae (30\% - 325 osobników), Isotomidae (18\% - 193 skoczogonki) i Brachystomellidae (11\% 116 osobników).

Roztocze. W próbach gleby pobranych z plantacji ziemniaka oznaczono łącznie 2856 roztoczy, natomiast 


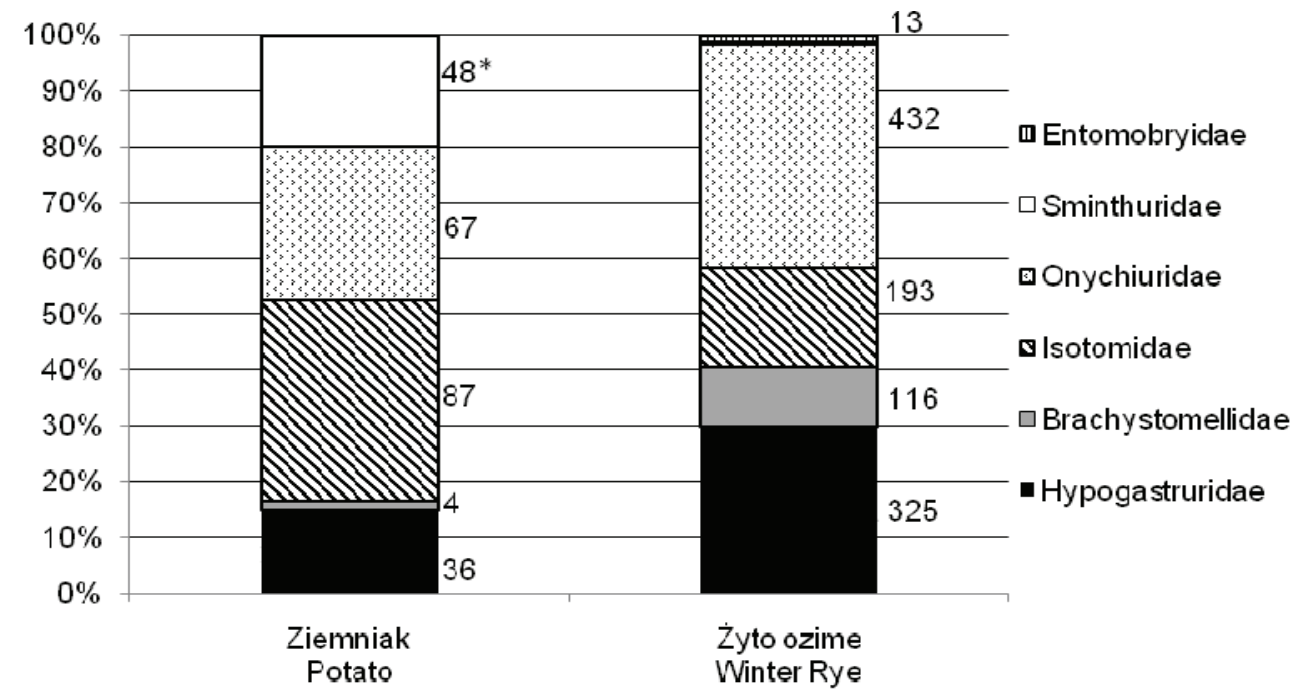

*liczebność skoczogonków oznaczonych do rodzin - number of springtails identified to family level

Rys. 1. Liczebność skoczogonków oznaczonych do rodzin w obu kombinacjach doświadczenia w latach 2010-2012

Fig. 1. The number of springtails identified to family level in both experiment treatments in 2010-2012

Tabela 1. Łączna liczebność skoczogonków w uprawie ziemniaka i żyta ozimego w latach 2010-2012

Table 1. Total number of springtails on potato and winter rye field in 2010-2012

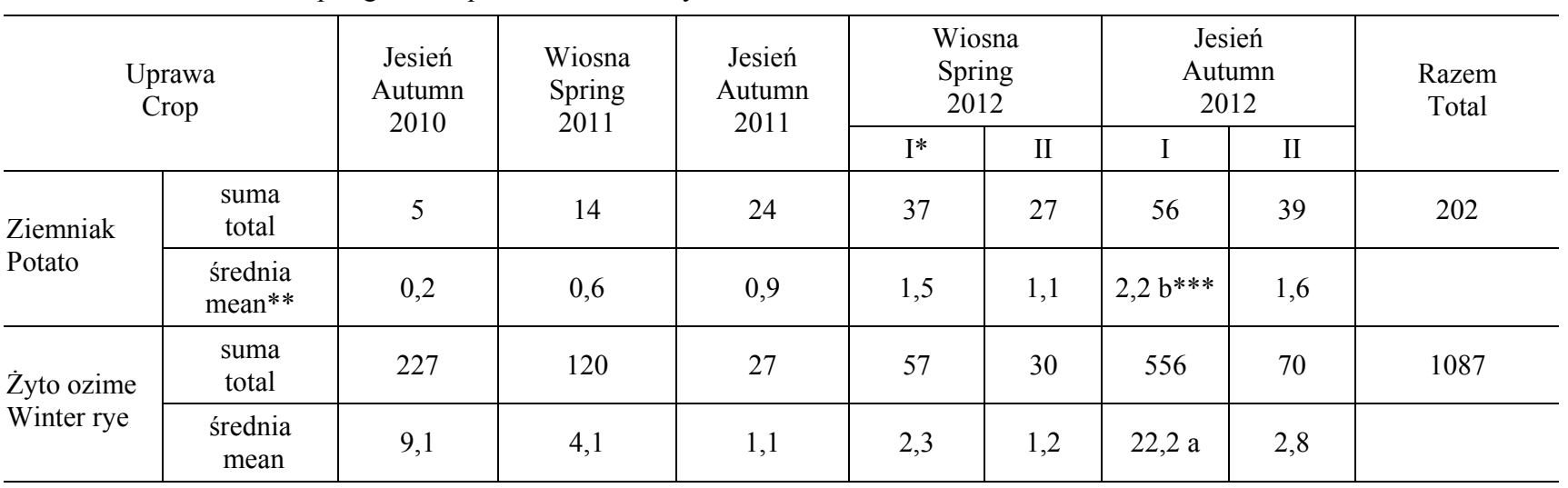

* terminy pobierania prób glebowych - soil sampling dates

** średnia liczba skoczogonków w jednej próbie - mean number of springtails in one sample

*** wartości średnich w kolumnach oznaczone różnymi małymi literami różnią się między sobą istotnie - means in columns followed by different small letters differ significantly

Tabela 2. Łączna liczebność roztoczy w uprawie ziemniaka i żyta ozimego w latach 2010-2012

Table 2. Total number of mites on potato and winter rye in 2010-2012

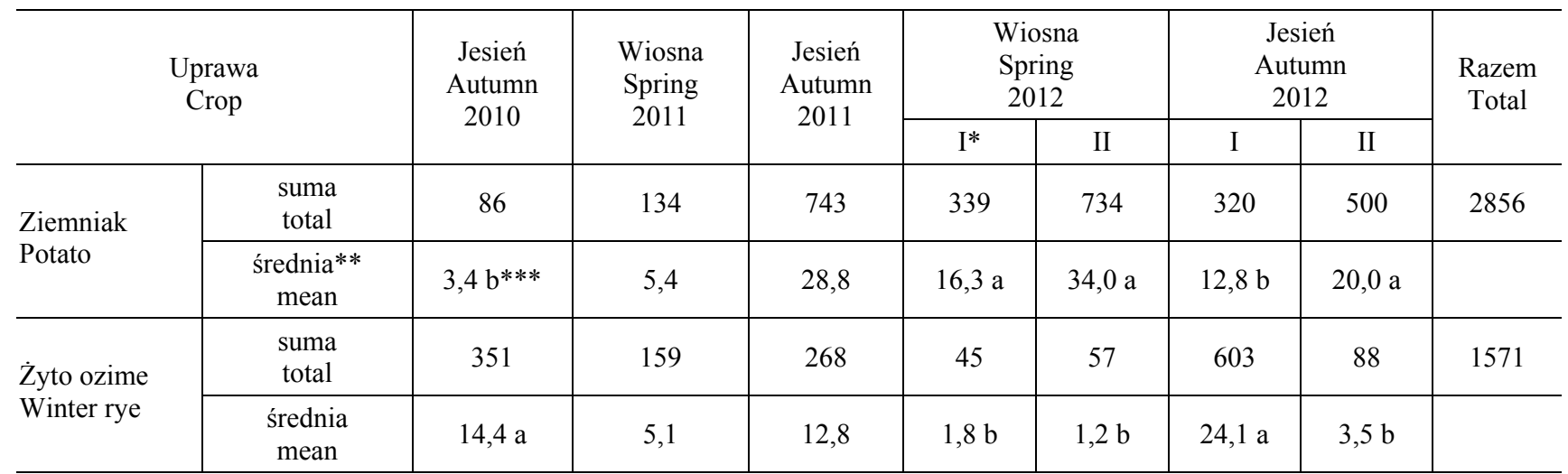

*terminy pobierania prób glebowych - soil sampling dates

**średnia liczba roztoczy w jednej próbie - mean number of mites in one sample

*** wartości średnich w kolumnach oznaczone różnymi małymi literami różnią się między sobą istotnie - means in columns followed by different small letters differ significantly 
Tabela 3. Liczebność roztoczy oznaczonych do rzędów

Table 3. The number of mites identified to order level

\begin{tabular}{|c|c|c|c|c|c|}
\hline $\begin{array}{l}\text { Uprawa } \\
\text { Crop }\end{array}$ & Prostigmata & Astigmata & Gamasida & Oribatida & $\begin{array}{l}\text { Razem } \\
\text { Total }\end{array}$ \\
\hline \multicolumn{6}{|c|}{ Jesień - Autumn 2010} \\
\hline Ziemniak - Potato & $35 \mathrm{~b}^{* *}$ & $5 \mathrm{~b}$ & 32 & $14 \mathrm{a}$ & 86 \\
\hline Żyto ozime - Winter rye & $183 \mathrm{a}$ & $37 \mathrm{a}$ & 61 & $70 \mathrm{~b}$ & 351 \\
\hline \multicolumn{6}{|c|}{ Wiosna - Spring 2011} \\
\hline Ziemniak - Potato & 37 & 43 & 35 & 19 & 134 \\
\hline Żyto ozime - Winter rye & 27 & 19 & 88 & 25 & 159 \\
\hline \multicolumn{6}{|c|}{ Jesień - Autumn 2011} \\
\hline Ziemniak - Potato & 540 & 104 & 85 & 14 & 743 \\
\hline Żyto ozime - Winter rye & 47 & 177 & 31 & 13 & 268 \\
\hline \multicolumn{6}{|c|}{ Wiosna - Spring 2012 I* } \\
\hline Ziemniak - Potato & $68 \mathrm{a}$ & $199 \mathrm{a}$ & 29 & 42 & 339 \\
\hline Żyto ozime - Winter rye & $1 \mathrm{~b}$ & $9 \mathrm{~b}$ & 18 & 17 & 45 \\
\hline \multicolumn{6}{|c|}{ Wiosna - Spring 2012 II } \\
\hline Ziemniak - Potato & $117 \mathrm{a}$ & $531 \mathrm{a}$ & $72 \mathrm{a}$ & 15 & 734 \\
\hline Żyto ozime - Winter rye & $13 \mathrm{~b}$ & $12 \mathrm{~b}$ & $21 \mathrm{~b}$ & 11 & 57 \\
\hline \multicolumn{6}{|c|}{ Jesień - Autumn 2012 I } \\
\hline Ziemniak - Potato & $163 \mathrm{a}$ & 82 & $41 \mathrm{~b}$ & $34 \mathrm{~b}$ & 320 \\
\hline Żyto ozime - Winter rye & $53 \mathrm{~b}$ & 181 & $200 \mathrm{a}$ & $167 \mathrm{a}$ & 601 \\
\hline \multicolumn{6}{|c|}{ Jesień - Autumn 2012 II } \\
\hline Ziemniak - Potato & $301 \mathrm{a}$ & $77 \mathrm{a}$ & $68 \mathrm{a}$ & 54 & 500 \\
\hline Żyto ozime - Winter rye & $21 \mathrm{~b}$ & $11 \mathrm{~b}$ & $24 \mathrm{~b}$ & 34 & 90 \\
\hline $\begin{array}{l}\text { Lączna liczba w uprawie ziemniaka } \\
\text { Total number in potato crop }\end{array}$ & 1261 & 1041 & 362 & 192 & 2856 \\
\hline $\begin{array}{l}\text { Łączna liczba w uprawie żyta ozimego } \\
\text { Total number in winter rye crop }\end{array}$ & 345 & 446 & 443 & 337 & 1571 \\
\hline
\end{tabular}

Total number in winter rye crop

*terminy pobierania prób glebowych - soil sampling dates

**wartości w kolumnach oznaczone różnymi małymi literami różnią się między sobą istotnie - values in columns followed by different small letters differ significantly

w próbach z uprawy żyta ozimego stwierdzono 1571 osobników tej podgromady (tab. 2). W trzech terminach badań (na siedem łącznie), organizmy te występowały istotnie liczniej w uprawie ziemniaka, aniżeli żyta ozimego. Tylko w dwóch terminach pobierania prób, tj. jesienią 2010 i w pierwszym terminie jesienią 2012 roku, istotnie więcej roztoczy odłowiono w uprawie żyta ozimego w porównaniu do uprawy ziemniaka.

Wypłoszone w aparatach Tullgrena roztocze oznaczono do czterech rzędów, tj. Prostigmata, Astigmata, Gamasida oraz Oribatida (tab. 3). Najliczniejszą grupą w uprawie ziemniaka były Prostigmata. Łącznie wypłoszono 1261 tych roztoczy. Mniej licznie w omawianej uprawie występowały Astigmata (1041 osobników), Gamasida (362 osobniki), a najrzadziej Oribatida (192 osobniki). W przypadku żyta ozimego stwierdzono najwięcej roztoczy z rzędu Astigmata (446 osobniki), mniej Gamasida (443 osobniki) i Prostigmata (345 osobników), a najmniej Oribatida (337 osobników). Roztocze z rzędu Prostigmata, w czterech terminach pobierania prób, istotnie liczniej występowały w uprawie ziemniaka, w porównaniu do żyta ozimego. W jednym terminie odnotowano odwrotną zależność. W przypadku Astigmata w uprawie ziemniaka, istotnie liczniej występowały one $\mathrm{w}$ trzech terminach badań, natomiast w uprawie żyta tylko w jednym terminie. Roztocze należące do rzędu Gamasida, w dwóch przypadkach (drugi termin wiosną 2012, drugi termin jesienią 2012), istotnie liczniej wykazano w ziemniaku, natomiast w jednym terminie (pierwszy termin jesienią 2012), istotnie więcej było ich w glebie, na której uprawiano żyto. Przedstawiciele rzędu Oribatida w dwóch terminach (jesienią 2010, pierwszy termin jesienią 2012), istotnie liczniej występowały w uprawie żyta.

W literaturze dość szczegółowo opisano wpływ zabiegów uprawowych lub systemów uprawy roli na mezofaunę glebową (Neave i Fox 1998; Twardowski i wsp. 2004; Twardowski 2010). Brakuje natomiast badań dotyczących znaczenia samej rośliny uprawnej, a szczególnie ziemniaka i żyta ozimego dla skoczogonków, czy roztoczy. Różnice w liczebności Collembola były szczególnie wyraźne jesienią. Znacznie więcej tych stawonogów odławiano wtedy w uprawie żyta ozimego 
w porównaniu do ziemniaka. W uprawie żyta stwierdzono również większą różnorodność taksonomiczną skoczogonków. Wśród oznaczonych Collembola wyróżniono przedstawicieli należących do rodzin: Hypogastrudidae, Brachystomellidae, Isotomidae, Onychiuridae i Sminthuridae oraz w uprawie żyta ozimego dodatkowo Entomobrydidae. Podobne wyniki uzyskali Frampton i Brink (2002), charakteryzujący zgrupowania epigeicznych skoczogonków w różnych uprawach i typach gleb. Autorzy ci zauważyli również, że $\mathrm{z}$ wyjątkiem jęczmienia, skoczogonki występują znacznie liczniej w zbożach ozimych, niż w uprawach jarych. Najniższą liczebność i różnorodność taksonomiczną omawianych stawonogów stwierdzono w uprawie roślin okopowych. Wyniki innych badań również wskazują na liczniejsze występowanie Collembola w zbożach ozimych w porównaniu do roślin okopowych (Jagers op Akkerhuis i wsp. 1988; Röske 1989; Sabatini i wsp. 1997). Frampton i Brink (2002), za Ogilvy (2001), uzasadniają stosunkowo niewielką liczebność Collembola w uprawach roślin jarych m.in. wytworzeniem niekorzystnego mikroklimatu (niskiej wilgotności i wysokiej temperatury gleby) podczas późnej wegetacji roślin, terminami wykonywania zabiegów uprawowych, stosowaniem wielu zabiegów ochrony roślin w przypadku niektórych upraw oraz zubożeniem gleby w materię organiczną w uprawie roślin okopowych. Smolis i Hurej (2001) stwierdzili, iż rodzaj uprawianej rośliny, poprzez typ systemu korzeniowego i sposobu ocieniania gleby, może wpływać na występowanie określonych zgrupowań skoczogonków. W niniejszych badaniach również wykazano, iż roślina uprawna może różnicować skład taksonomiczny Collembola. W życie ozimym stwierdzono stosunkowo duży udział skoczogonków z rodziny Onychiuridae. Organizmy te, charakteryzujące się brakiem oczu i pigmentacji ciała, zaliczane są do form zamieszkujących niższe warstwy gleby (Gisin 1943; Gruss i Twardowski 2012). Pozostałe skoczogonki wykazane w uprawie żyta ozimego (Hypogastrudidae, Isotomidae i Brachystomellidae), można w większości zaliczyć do form pośrednich bytujących w powierzchniowych warst- wach gleby. W ziemniaku udział skoczogonków z rodziny Onychiuridae był znacznie niższy niż skoczogonków epigeicznych, występujących bliżej lub na powierzchni gleby, tj. rodziny Sminthurididae.

W przypadku roztoczy stwierdzono liczniejsze ich występowanie w uprawie ziemniaka, aniżeli żyta ozimego. Badania niektórych autorów wskazują, iż grupą najbardziej wrażliwą na zmianę sposobu uprawy roli są przedstawiciele mechowców Oribatida (Wallwork 1976; Werner i Dindal 1990). Na podstawie badań własnych można stwierdzić, iż roztocze z rzędu Oribatida są również grupą wrażliwą w stosunku do rośliny uprawnej. Stawonogi te, podobnie jak roztocze $\mathrm{z}$ rzędu Gamasida istotnie liczniej występowały w uprawie żyta ozimego. W przypadku roztoczy z rzędu Prostigmata zauważono wyraźną preferencję w stosunku do uprawy ziemniaka.

\section{Wnioski / Conclusions}

1. We wszystkich terminach pobierania prób skoczogonki były znacznie liczniejsze w uprawie żyta ozimego w porównaniu do uprawy ziemniaka. W próbach pochodzących z ziemniaka stwierdzono występowanie skoczogonków należących do rodzin: Hypogastrudidae, Brachystomellidae, Isotomidae, Onychiuridae i Sminthuridae, natomiast $\mathrm{w}$ uprawie żyta ozimego dodatkowo oznaczono przedstawicieli rodziny Entomobrydidae.

2. Średnia liczebność roztoczy była wyraźnie wyższa w uprawie ziemniaka niż żyta ozimego. W przypadku rośliny okopowej najliczniej stwierdzano przedstawicieli rzędów Prostigmata i Astigmata, natomiast w przypadku żyta ozimego Astigmata i Gamasida.

Część badań przeprowadzono w ramach projektu badawczego NN310303139 finansowanego przez Ministerstwo Nauki i Szkolnictwa Wyższego.

\section{Literatura / References}

Alvarez T., Frampton G., Goulson D. 2001. Epigeic Collembola in winter wheat under organic, integrated and conventional farm management regimes. Agric. Ecos. Environ. 83: 95-110.

Axelsen J.A., Thorup-Kristensen K.T. 2000. Collembola and mites in plots fertilized with different types of green manure. Pedobiologia 4: $556-566$.

Behan-Pelletier V. 1999. Oribatid mite biodiversity in agroecosystems: role for bioindication. Agric. Ecos. Environ. 74: 411-423.

Boczek J., Błaszak Cz. 2005. Roztocze (Acari) - znaczenie w życiu i gospodarce człowieka. Wyd. SGGW, Warszawa: 7-30.

Buscot F., Varna A. 2005. Microorganisms in Soil: Roles in Genesis and Functions. Soil Biology. Springer, Berlin: 259-262.

Edwards C. 1999. Soil Invertebrate Controls and Microbial Interactions in Nutrient and Organic Matter Dynamics in Webmaster Functions in Agroecosystems: Invertebrates. Climate and Substrate Quality. CABI Publishing, Wallingford: 141-159.

Filser J., Fromm H. 1995. The vertical distribution of Collembola in an agricultural landscape. Pol. Pismo Entomol. 64: 99-112.

Frampton G., Brink P. 2002. Influence of cropping on the species composition of epigeic Collembola in arable fields. Pedobiologia 46: $328-337$.

Gisin H. 1943. Ökologie und Lebensgemeinschaften der Collembolen im Schweizerischen Exkursionsgebiet Basels - Rev. Suisse Zoologique 50: 131-224.

Gruss I., Twardowski J. 2012. Ilościowa i ekologiczna charakterystyka zgrupowań skoczogonków (Hexapoda: Collembola) na plantacji żyta ozimego uprawianego w wieloletniej monokulturze i pięciopolowym płodozmianie. J. Res. Appl. Agric. Engin. 57 (3): $129-132$.

Hopkin S. 2007. A Key to the Collembola (Springtails) of Britain and Ireland. AIDGAP: Shrewsbury, UK, 245 pp. 
Jagers op Akkerhuis G., De Ley F., Zwetsloot H., Ponge J., Brussaard L. 1988. Soil microarthropods (Acari and Collembola) in two crop rotations on a heavy marine clay soil. Rev. Ecol. Biol. Soil 25: 175-202.

Koehler H.H. 1999. Predatory mites (Gamasina, Mesostigmata). Agric. Ecos. Environ. 74: 395-410.

Luxton M. 1982. Quantitative utilization of energy by the soil fauna. Oikos 39 (7): 342-354.

Murphy P.W. 1956. A modified funnel method for extracting soil mesofauna. Trans. 6th Int. Congr. Soil Sci., Paris, C: $255-262$.

Neave P., Fox C. 1998. Response of soil invertebrates to reduced tillage systems established on a clay loam soil. Appl. Soil Ecol. 9: 423-428.

Neher D., Barbercheck M. 1999. Diversity and function of soil mesofauna. p. 27-47. In: "Biodiversity in Agroecosystems" (W. Collins, C. Qualset, eds). CRC Press LLC, Boca Raton, 352 pp.

Ogilvy S.E. 2001. Experiment design, treatments, monitoring and pesticide use. p. 199-217. In: "Reducing Agrochemical Use on the Arable Farm" (J. Young, D. Alford, M. Griffin, S. Ogilvy, eds). UK Department for Environment, Food and Rural Affairs, 416 pp.

Pomorski J. 1998. Onychiurinae of Poland (Collembola: Onychiuridae). Polish Taxonomical Society, Wroclaw, 201 pp.

Potapov M. 2001. Synopses on Palaearctic Collembola: Isotomidae. Abhandlungen und Berichte des Naturkundemuseums Görlitz 73 (2): 1-603.

Röske H. 1989. Collembola fauna on different types of agriculturally used soil. p 283-290. In: 3rd International Seminar on Apterygota. Italy, Siena, 21-26 August 1989, 489 pp.

Rusek J. 1998. Biodiversity of Collembola and their functional role in the ecosystem. Biodiversity and Conservation 7: $1207-1219$.

Sabatini M.A., Rebecchi L., Cappi C., Bertolani R., Fratello B. 1997. Long-term effects of three different continuous tillage practices on Collembola populations. Pedobiologia 41: 85-193.

Smolis A., Hurej M. 2001. Charakterystyka porównawcza składu gatunkowego Collembola pól rzepaku ozimego i pszenicy ozimej w okolicy Wrocławia. Zesz. Nauk. AR Wrocław, Rolnictwo 78: 129-137.

Twardowski J. 2010. Wpływ uproszczeń w uprawie roli pod pszenicę ozimą na zgrupowania stawonogów epigeicznych i glebowych. Monografie CVII, Wydawnictwo UP Wrocław, 141 ss.

Twardowski J., Smolis A., Kordas L. 2004. Wpływ różnych systemów uprawy roli na mezofaunę glebową. Badania wstępne. Ann. UMCS 59: 817-824.

Wallwork J. 1976. The Distribution and Diversity of Soil Fauna. Academic Press, London, 355 pp.

Werner M., Dindal D. 1990. Effects of conversion to organic agriculture practices on soil biota. Am. J. Alternat. Agric. 5, p. 24. 